\title{
Contra el agandalle de la tira. El surgimiento del Movimiento de Liberación Homosexual y la resistencia a la razias policiacas en la ciudad de México, 1978-1984¹
}

\author{
Contra el agandalle de la tira. The emergence of the Homosexual Liberation Movement \\ and the resistance against police raids in Mexico City, 1978-1984.
}

\author{
MARTíN H. GONZÁLEZ \\ El Colegio de México \\ mhgonza@colmex.mx, \\ https://orcid.org/0000-0003-3787-0731 \\ http://dx.doi.org/10.15304/sm.31.6003
}

\section{RESUMEN}

Este artículo estudia la resistencia a la represión policiaca durante los primeros años del Movimiento de Liberación Homosexual (MLH) en la ciudad de México. Tomando como fuente principal la prensa del período, se analiza la forma en que el MLH se organizó para responder a las redadas recurrentes, así como las estrategias cotidianas de resistencia que los sujetos implementaron para enfrentarse a la autoridad. En el texto se busca poner a prueba el marco conceptual de la resistencia y de las herramientas de los débiles aportado por James C. Scott. Los resultados de este ejercicio invitan a pensar en el MLH como una respuesta a la agudización de la violencia y la represión policiaca, resultado del crecimiento urbano y la aparición de mercados y espacios nocturnos de socialización específicamente homosexual.

Palabras clave: policía, homosexualidad, represión, resistencia, movilización.

\section{Abstract}

This paper studies the resistance to police repression during the first years of the Homosexual Liberation Movement in Mexico City. With newspapers as a main historical source, it analyzes how the Movement organized to confront recurrent police raids, as well as individual resistance strategies implemented to cope with the authorities. The paper pretends to put James C. Scott's concepts of

1 Este artículo es producto de las reflexiones surgidas en el seminario "Historia desde abajo", impartido por la Dra. Romana Falcón en El Colegio de México. Agradezco a Romana Falcón y a mis compañeros por sus valiosos comentarios y aportaciones. 
resistance and the weapons of the weak to test. The results of this exercise invite us to think of the Homosexual Liberation Movement as a response to a peak in police violence and repression, caused by a growing urbanization and the emergence of specifically homosexual markets and night-life sociability spaces.

Keywords: police, homosexuality, repression, resistance, mobilization.

El 17 de marzo de 1979, en el suplemento Sábado del diario Unomásuno, se podía leer una opinión editorial del escritor mexicano José Joaquín Blanco. «Ojos que da pánico soñar» se convertiría en uno de los textos considerados fundacionales de la cultura gay en México, porque en sus páginas el escritor reconocía públicamente su homosexualidad. Además de la salida del clóset, el texto contenía una cruda autocrítica a la comodidad de los hombres homosexuales de clase media en la ciudad de México. Así, Blanco hacía referencia al incipiente mercado que comenzó a configurarse en los espacios de socialización gay de la capital durante la década de los setenta. La opinión que tenía el escritor de ese estilo de vida citadino -conformado por hombres más o menos acomodados, ávidos del anonimato que les permitiera entablar sus relaciones sexuales y afectivas lejos de la mirada de la familia y el trabajo- no era para nada positiva. «Fuera de esos negocios prósperos, incluso para protegerlos, la persecución continúa igual» (Blanco, 2010: 257).

Aquí se refería, sin duda, a una experiencia compartida por muchos hombres homosexuales a lo largo del siglo XX que, al tratar de entablar sus relaciones, debieron enfrentar no sólo el rechazo, sino la represión y la persecución por parte de la autoridad en los espacios públicos. El fenómeno no significaba solamente una reacción represiva ante la expresión explícita del deseo homoerótico que desafiaba a la cultura heterosexual dominante. La persecución y represión pusieron en peligro a los sujetos simplemente por su aparición en el espacio público. Al transgredir las normas de género con su afeminamiento -que para los agentes policiacos era evidencia de su homosexualidad-numerosos homosexuales fueron violentados, perseguidos y consignados a la autoridad. ${ }^{2}$ Sumada a otros fenómenos sociales de violencia, la represión policiaca dio un carácter oficial y sistemático al hostigamiento a los homosexuales. Al ponderar estos asuntos, las palabras de Blanco son casi proféticas:

«Sospecho que dentro de unos años, cuando la cantidad de homosexuales capitalinos sea mucho mayor, y por lo tanto más fuerte en la opinión pública, tendrá que disminuir la persecución policiaca contra los homosexuales de nuestra clase, pero a los homosexuales jodidos se les seguirá explotando igual» (Blanco, 2010:257).

2 Este fenómeno forma de hecho una parte central del trabajo teórico de Judith Butler (2009) en torno a la performatividad de género. En un texto que profundiza sus postulados más clásicos, Butler explica cómo su preocupación por la performatividad se relaciona con un fenómeno más amplio de «precariedad». Al existir de determinadas formas en el espacio público, ciertos sujetos son rechazados, expuesto al insulto y la extrema violencia, hasta ser reducidos a algo menos que humanos. 
«Ojos que da pánico soñar» no fue una expresión aislada. El año anterior, en 1978, la ciudad vio surgir el Movimiento de Liberación Homosexual (MLH) e iniciarse un período de intensa actividad. Aunque desde principios de la década se habían comenzado a conformar grupos homosexuales de diversa índole, el año de 1978 fue trascendental. Un pequeño contingente de una agrupación llamada Frente Homosexual de Acción Revolucionaria (FHAR) salió a las calles por primera vez ese 26 de julio, en una manifestación que conmemoraba el asalto militar que dio origen al movimiento revolucionario en Cuba. Meses después, se sumaron un puñado de organizaciones lésbico-gay y adquirieron visibilidad uniéndose a la marcha que recordaba diez años de la represión del Movimiento Estudiantil en la Plaza de Tlatelolco. ${ }^{3}$ La primera Marcha del Orgullo, que se celebró al año siguiente, dio origen a una tradición de movilización y resistencia (Díez, 2010: 240243 y Brito, 2010: 240-243).

La preocupación de Blanco por los «homosexuales jodidos» es de hecho característica de este primer período de movilización homosexual en México, en el que sus agrupaciones buscaron asociarse con partidos políticos de izquierda, como el Partido Revolucionario de los Trabajadores (PRT) y el Partido Socialista Unificado de México (PSUM), así como con distintas organizaciones sindicales. El principal interés de trabajo del FHAR, «eran los sectores marginados de la comunidad homosexual, tales como travestis, transexuales, mayates y chacales, a quienes había que rescatar» (Salinas Hernández, 2008: 52). ${ }^{4}$ Independientemente de la ideología política, la naturaleza de la represión hacía concordar los intereses del activismo homosexual con el de los sectores más desfavorecidos de la sociedad. Y es que «la calle ha sido de manera poderosa (...) el eje de la vida homosexual» (Bautista, 2010: p. 2016) y la noche el cobijo necesario para establecer relaciones y socializar fuera de la mirada represora. Esta condición de marginalidad emparentó a los grupos homosexuales -conformados por jóvenes educados de clase media-con diversos sectores vulnerables - prostitutas, vagos y nuevas culturas juveniles- como víctimas de redadas y persecuciones policiacas en las décadas de los 70 y 80.

Con esto en mente, resulta sugerente estudiar los primeros años del MLH en México comprendiéndolo como parte de una gama de esfuerzos que un heterogéneo grupo de sujetos implementó para resistirse a la represión policiaca. Después de todo, los llamados

3 Durante los primero años de movilización aquí estudiados, la organización lésbica Oikabeth y el Grupo Lambda de Liberación Homosexual unieron fuerzas con el Frente Homosexual de Acción Revolucionaria (FHAR) para combatir la represión y promover la liberación homosexual. En este artículo me refiero más particularmente a acciones emprendidas por el FHAR, cuyas agenda política estaba basada en una reflexión marxista de la clase. Sin embargo, algunas de las acciones aquí referidas, como las paradas de protesta, fueron emprendidas de manera conjunta.

4 El FHAR reivindicó el travestismo como un componente de su ideal de liberación homosexual y se solidarizó con las «vestidas», por considerarlas el sector más vulnerable a la violencia y la represión. Esta postura desató no pocas polémicas. Acercarse al estudio de los sujetos travesti implica un reto metodológico, porque su aparición en los archivos se encuentra comúnmente mediada por otras voces. Considero que este es un tema que requiere atención particular, por lo que actualmente me encuentro trabajando en un artículo que lo aborda. 
a la manifestación pública de esta época contenían a menudo mensajes que invitaban a expresarse contra la persecución de «la tira» y enfrentarse a las redadas. Enfocar la mirada en la represión de la autoridad permite complementar los enfoques que se han concentrado en entender el MLH desde el marco interpretativo de los movimientos sociales, la organización y la acción colectiva. ${ }^{5}$ Con suerte, esto ayudaría además a iluminar las complejidades de clase inherentes a la situación de los homosexuales y a su movilización en el período que va de 1978 a $1984 .^{6}$

La historiografía sobre el MLH normalmente enfatizan las influencias internacionales de las que se nutrió el MLH en México, pues los disturbios de Stonewall en Estados Unidos despertaron un reclamo social y promovieron «un discurso 'liberacionista' basado en la necesidad de quitarse el estigma social, la represión y eliminar obstáculos a la libre expresión de la sexualidad» (Díez, 2010: 138). Sin embargo, sería importante recordar que los sucesos de Stonewall, que se consideran el germen de un movimiento de liberación organizado, fueron precisamente detonados por la resistencia de un grupo de homosexuales, lesbianas, transexuales y travestis que se enfrentaron a la violencia policiaca durante una redada en un bar de Nueva York. En ese sentido, parece necesario superar la lógica del contagio político para reconocer que ese discurso liberacionista se pudo articular en otros contextos -como en México- precisamente porque el fenómeno de represión, y su respectiva resistencia, eran una experiencia compartida en distintos entornos urbanos. ${ }^{7}$

Por otra parte, la historiografía reciente sobre la homosexualidad se ha esforzado en enfatizar los espacios de libertad, la subcultura y las redes de sociabilidad con que contaron los sujetos aun antes de la aparición de los movimientos de liberación. El estudio de Chauncey (1994) para Nueva York insiste en que los movimientos políticos modernos han desarrollado una serie de mitos sobre el pasado de la homosexualidad. Caracterizándola como una experiencia aislada y reprimida, estos mitos han contribuido a su olvido. Al contrario, recientemente se ha puesto el acento en la vitalidad de los espacios de convivencia homosexual a lo largo del siglo XX. Siguiendo esas misma premisa, el trabajo de Rodríguez Sánchez (2018) confirma la existencia de estos espacios en la ciudad de México antes del MLH mexicano. El estudio de Huard (2014), que se concentra en París

5 Para un recuento tradicional del Movimiento de Liberación Homosexual en México, que se enfoca en la labor política de sus organizaciones, véase Díez (2010). Para un acercamiento al Movimiento desde el marco interpretativo de la acción colectiva, que además problematiza el concepto de identidad, véase Argüello Pazmiño (2014).

6 Esta periodización coincide con una cronología propuesta por Díez (2010), en la que los años entre 1978 y 1984 corresponden a un momento de «gestación, surgimiento y fortalecimiento del movimiento». Díez caracteriza los años posteriores como un período de declive, en la que la imagen y la fuerza de las organizaciones mermó por la crisis del VIH-SIDA, y en la que además concentraron sus esfuerzos en combatir la pandemia.

7 Para un estudio de más largo aliento sobre el MLH, en el que se considera ampliamente el tema de la represión policiaca, véase el trabajo comparativo entre México y Brasil elaborado por De la Dehesa (2010). 
y Barcelona, suscribe también esta postura y critica los planteamientos revolucionarios y liberacionistas de la homosexualidad que estuvieron en boga durante la década de los setenta, pues considera que menoscabaron los esfuerzos de las agrupaciones «homófilas» por reclamar mayor dignidad.

Pero además de estudiar las posturas políticas del MLH, podríamos también acercarnos a la realidad más cotidiana de sujetos que, aunque no necesariamente fueron ajenos a la militancia y la organización del MLH, debían ingeniárselas con otros recursos y estrategias para sobrevivir a las llamadas razzias $^{8}$ en su intento por entablar relaciones de sociabilidad homosexual. Aunque en el período que comprende este estudio se plantearon exigencias que confrontaban directamente las normas sociales de la época, una situación concreta de represión en las calles y centros nocturnos obligaba a buscar formas de resistencia. Para sobrevivir a la persecución y a la violencia de la autoridad, estos individuos debieron implementar estrategias y echar mano de recursos que no confrontaban directamente a la autoridad, sino que estaban destinados a sobrevivir la represión. En el camino, el reconocimiento de estas dinámicas invita a preguntarse qué cambió antes y después del MLH. ¿Por qué las estrategias de resistencia cotidiana que hasta entonces habían permitido sostener una subcultura homosexual con cierta vitalidad dejaron de ser suficientes? ¿Por qué se pasó de la resistencia a la protesta?

Para echar luz sobre esto, resulta útil referirse al marco interpretativo aportado por James C. Scott en torno a las «armas» de los más débiles. Aunque Scott toma como base de su teoría, principalmente, las acciones de las sociedades campesinas para sobrevivir a la explotación, su propuesta es útil en este caso porque enfatiza todas aquellas acciones que, aunque no confrontan directamente a la autoridad, permiten resistirse a los efectos de una situación de subordinación. Si para los campesinos evadir la confrontación con la autoridad era necesario para asegurar la supervivencia, dado el abasto mínimo de recursos, para los homosexuales citadinos esto era igualmente importante, ante la amenaza de violencia que también ponía en peligro sus vidas (Scott, 1976; Scott, 2014).

A continuación se pone a prueba el marco conceptual de la resistencia para el estudio de esta primera etapa de movilización política, enfatizando las demostraciones específicas de repudio a las redadas contra la población homosexual. En el camino, se pretende un acercamiento a las redadas mismas y a las formas en que se resistió a la persecución policiaca. ${ }^{9}$ Primero, se abordan las formas en que la identidad y la socialización homosexual

8 La palabra «razia» es un préstamo lingüístico del francés, a su vez tomado del argelino, que, según la Real Academia Española, significa una «correría en un país enemigo y sin más objeto que el botín». Una segunda acepción es, simplemente, una «redada». Su incorporación al español y el uso equivocado razzia, como en francés (y en inglés), fue común seguramente por el contexto internacional de movimientos sociales, como el de las movilizaciones estudiantiles del 68.

9 Este texto centra su atención, principalemente, en las estrategias de resistencia que los sujetos desplegaron en el contexto de los primero años de movilización homosexual. Para esto, se recurre al marco analítico mencionado. Sin embargo, la naturaleza de la violencia policiaca merece una interpretación más profunda. Esta interpretación podría beneficiarse de una lectura foucaultiana, que atienda a las nociones de poder y disciplina. 
pueden concebirse como elementos de una cultura de resistencia. Algunas reflexiones sobre los estilos de vida de hombres homosexuales en el México del siglo XX dejan entrever estrategias que harían tolerables las situaciones de represión. Posteriormente, se presenta un recuento de la movilización política homosexual del período, específicamente aquella que estuvo motivada por una reacción hacia la persecución policiaca. Finalmente, se enfoca la mirada hacia las estrategias específicas de resistencia que marcaron la lucha contra los agentes policiacos en las calles de la ciudad de México durante el período estudiado. Esta aproximación invita a tender puentes entre el estudio de la represión a la población homosexual y otros referentes más tradicionales en el marco analítico de los estudios de grupos marginados y explotados. Además, permite repensar al MLH de los años 70 y 80, ponderando las luchas específicas que marcaron su sentido de urgencia.

Para realizar este análisis se ha recurrido, además de las fuentes secundarias, a la documentación que las propias agrupaciones homosexuales de la época recabaron en su momento y que hoy se conservan en el archivo del Centro Académico de la Memoria de Nuestra América (CAMENA). ${ }^{10}$ Los documentos, agrupados bajo el rubro de «razzias», dan cuenta del interés de las agrupaciones por evidenciar la persecución policiaca y enfrentarse a ella. Salvo por algunas hojas volantes y documentos de trabajo, dominan los recortes de periódicos que reportan las razias y los reclamos a las autoridades. Aunque están mediados por el discurso periodístico y sus respectivas tendencias editoriales, los documentos hemerográficos reproducen también ricos y variados testimonios de los hechos, de los que es posible recuperar una mirada a ras de suelo. Este estudio, sin embargo, no ha considerado la recolección de información testimonial ad hoc de los protagonistas de MLH. También excede a sus propósitos las búsqueda en los registros policiacos. De todos modos, como las fuentes hemerográficas sugieren, es posible que en éstas se encuentre, en el mejor de los casos, cargos falsos y cifras maquilladas, que encubren la corrupción de los agentes policiacos.

Sin duda, este tema requeriría de una investigación más exhaustiva. Sin embargo, aquí se ensaya una propuesta de aproximación que invita a continuar la labor. Aunque resulte limitado, el estudio de la mencionada carpeta «razzias» da cuenta de la forma en que el propio archivo -a través de sus distintas etapas de resguardo y catalogación-indica los temas que preocupaban a los militantes de la liberación homosexual.

\section{UNA CULTURA PROPIA. DISCURSO OCULTO Y RESISTENCIAS ANTES DEL MLH}

Los estudios históricos sobre homosexualidad han estado marcados por la dificultad metodológica que implica considerar la dimensión de clase en la socialización y en la

10 Estos documentos se encuentra en el Fondo I del CAMENA gracias a los donativos del Centro de Documentación y Archivo Histórico Lésbico «Nancy Cárdenas» y del Colectivo Sol. 
conformación de la identidad de los sujetos. El concepto «gay» ya supone ciertas dificultades, pues comprende una visión moderna de la orientación sexual post-Stonewall, marcada por la celebración de la identidad, un carácter transnacional y una cultura de consumo (Weeks, 2012). En México, Carlos Monsiváis, quien ha hecho esfuerzos por superar la carencia de fuentes para realizar una historia de la homosexualidad en México, ha advertido que sus notas al respecto normalmente se centran en los sectores medios y de la burguesía. «Por buenas o malas razones ellos representan al conjunto de la vida gay, mientras la indagación histórica no diga lo contrario» (Monsiváis, 2010: 109-110). Y en efecto, rastrear la vida de sujetos homosexuales antes de los pronunciamientos frontales del MLH obliga a acercarse a determinados circuitos sociales de los que queda registro. Sin embargo, algunos estudios sobre socialización homosexual en grandes urbes dan cuenta de toda una subcultura, marcada en gran medida por la interacción entre distintas clases sociales, facilitada por la clandestinidad, el anonimato urbano y la movilidad masculina (Chauncey, 1994; Beachy, 2014; Huard, 2014; Rodríguez Sánchez, 2018). De hecho, los mismos diarios y cartas del escritor Salvador Novo y el médico y poeta Elías Nandino, de las que Monsiváis nutre sus reflexiones, muestran una clara interacción social, sexual y afectiva entre clases sociales. Ésta, sin embargo, no está exenta de su respectiva dosis de poder.

Para Monsiváis, en la primera parte del siglo XX los «gays de clases populares o de clase media baja (...) no tienen oportunidades de actuar», mientras los «gays de dinero y/o prestigio establecen el gueto, el universo subterráneo» (Monsiváis, 2010: 110). En todo caso, existió una subcultura que unió, en su marginación, a homosexuales de distintos sectores sociales. Es posible imaginar que hombres de todas clases sociales participaron de los códigos compartidos que les permitieron hacerse de un mínimo espacio para establecer sus relaciones, sin enfrentarse directamente a la cultura dominante. Estos códigos culturales, que en muchos casos tienen a la noche como un común denominador, se pueden entender como un mecanismo de resistencia, en tanto «la lucha no está marcada tanto por las confrontaciones masivas y desafiantes como por una evasión silenciosa que es igualmente masiva y efectiva» (Scott, 2014: 96). Se trata de un mundo de afirmación de la identidad dentro de los límites de una cultura dominante, en el que se establece un vínculo directo con el mundo «de abajo». Así, los espacios que visitaban los homosexuales antes del MLH normalmente fueron «tugurios y antros de mala muerte», «algunos un poco por esnobismo en sentido contrario, pero la mayoría porque la condición marginal no permitía otras opciones y porque en este tipo de ambientes encontraban menos hipocresía y hasta cierto cobijo» (Bautista, 2010: 217).

Aunque no es el propósito de esta investigación agotar este tema, entender las características de la cultura homosexual como el producto de estrategias de resistencia ayuda a dar una visión panorámica y ofrecer una nueva lectura del MLH. En este sentido, aquí se pretende enfatizar la existencia de formas de resistencia a la represión sistemática de los homosexuales, incluso antes del MLH y conviviendo con éste. A diferencia de las reivindicaciones políticas y la confrontación directa que implicó la movilización, esta 
resistencia procuró paliar los efectos de la represión sin enfrentarse a las estructuras de poder dominante. Así, siguiendo el concepto de economía moral acuñado por Thompson (1971) y retomado por Scott (1976), cabría imaginar que, más allá del contagio ideológico de la liberación gay, algo se fracturó en las relaciones de poder preexistentes e hizo intolerable una marginación cuando antes no lo era.

Las caracterizaciones hechas de la cultura homosexual dan cuenta de algunos rasgos de esta resistencia. Entre ellas destaca la construcción de códigos secretos de comunicación para reconocerse entre iguales. Para Monsiváis (2010: 113), «[e]l entendido domina los secretos: quiénes son sus semejantes, en qué consisten las reuniones, cuál es el idioma secreto (...)». Como dan cuenta algunas investigaciones sobre la transformación urbana de la ciudad de México, antes de que aparecieran los primeros espacios de socialización destinados a un mercado de consumo homosexual en los 70 (Boivin, 2013), los sujetos extendían este conocimiento secreto en los espacios marginales, replegándose a sitios de trasiego popular. «Es impensable que se tratara de bares ostentosamente homosexuales, de ninguna manera 'gays' en el sentido actual del término, pero sin duda debieron ser sitios tomados por tal concurrencia y reconocidos por los noctámbulos como tales» (Bautista, 2010: 218). Sin confrontar ni negar su carácter de marginados, estas estrategias permitieron a los sujetos hacer más llevadera su vida.

Destaca también la caracterización de la cultura homosexual como una que a menudo se apropia del lenguaje denigratorio con el que se le insulta. Resignificar estas ofensas con humor forma parte de mecanismos que refrendan el orden imperante, retorciéndolo para hacerlo tolerable. «Con gestos, frases e ingenio muy entrenado, se trazan las psicologías que mezclan lo autocelebratorio con la autodenigración» (Monsiváis, 2010: 111-112). A menudo, esto tuvo una dimensión de género, en la que los hombres homosexuales refrendaban el discurso médico de la «inversión» sexual, asumiendo también las concepciones tradicionales de superficialidad de lo femenino. «Ser afeminado es asumir de antemano la condición del vencido y transformarla hasta donde se puede en las victorias de la forma sobre cualquier pretensión de contenido» (114). Monsiváis (2010) sugiere, además, que la elección de profesiones determinadas significó un mecanismo de protección importante. «En este trabajo, mi manera de ser importa menos» (132). Muy significativamente, también, considera que a través de la música de bolero en la década de los 50, la cultura homosexual logró asomarse secretamente. «La idea de filtrar lo gay calificándolo de mundo raro o de ‘amor extraño' (lo queer), es una de tantas estrategias para decir la verdad».

Estas descripciones muestran fuertes semejanzas con lo que Scott llama «discurso oculto», una dimensión privada del discurso de los dominados que prueba que su deferencia hacia sus opresores no es absoluta. Además, «una versión parcialmente esterilizada, ambigua y codificada del discurso oculto está siempre presente en el discurso público de los subordinados» (Scott, 2010: 43). Sin duda, las estrategias aquí planteadas incluyen su debida dosis de reivindicación, un reclamo del derecho a relacionarse con libertad, a no ser insultado y a ser reconocido públicamente. 
Con todo, los homosexuales aceptaron comúnmente la represión en que vivían antes de la aparición del MLH. Esta aceptación de la marginalidad podría ser el producto del cálculo estratégico en el que se sopesaban las consecuencias de la «insurrección». Incluso en la primera mitad del siglo XX, en los espacios de socialización homosexual, «los asistentes temen las redadas y por eso llevan dinero extra y prescinden de anillos y relojes costosos» (Monsiváis, 2010: 124). ¿Por qué surge, entonces, el descontento por las redadas contra homosexuales en las décadas de los 70 y 80 ? ¿Qué es lo que provoca «la ruptura del cordon sanitaire entre el discurso oculto y el público» (Scott, 2010: 43)?

\section{LA PRIMERA LIBERACIÓN HOMOSEXUAL Y SU ACCIÓN CONTRA LAS RAZIAS}

El sábado 23 de septiembre de 1978, la ciudad de México vivió una noche de arbitrariedad y violencia policiaca. El FHAR se apresuró a denunciar el suceso en una publicación socialista, en la que informó que esa noche «las fuerzas policiacas allanaron arbitrariamente e ilegalmente un centro nocturno frecuentado mayoritariamente por homosexuales y lesbianas, y sin mediar falta ni delito secuestró a más de doscientos parroquianos». Además, en su comunicado la organización informaba que había decidido realizar una parada de protesta en la explanada de la delegación Cuauhtémoc, «para demandar el cese a la represión sexista, y por ello anticonstitucional». ${ }^{11}$ Esa misma noche, el escritor y periodista Luis González de Alba -quien había participado en el Movimiento Estudiantil del 68- se preparaba para salir de fiesta a «El Topo», junto al Monumento a la Revolución. «El letrero 'club privado' es sólo un argumento contra las exigencias policiacas o la sorpresa de algún cliente». El periodista pasaría esa noche detenido en la delegación tras haber sido trasladado desde el bar en un coche sin placas. Su crónica de los sucesos aparecería a los pocos días en el diario Unomásuno. La historia terminó a las 4:30, con un final relativamente feliz: «subimos las escaleras... y nos ponen en la calle sin más trámite. Ni explicaciones, ni disculpas, ni multas, ni nada». ${ }^{12}$

Una manifestación convocada por el FHAR se realizaría el viernes siguiente a las 16:30 frente a la delegación, en Buenavista. «Según opiniones de varios abogados de la DGPT [Dirección General de Policía y Tránsito], el ser homosexual no es delito, pero si [sic] andar vestido de mujer en la calle comerciando el cuerpo, ya que se está incurriendo en faltas a la moral y el delito de lenocinio», ${ }^{13}$ informaba el Diario de México. «Durante el mitin de protesta, los citados quejosos harán entrega al licenciado Cuauhtémoc Santana, delegado en Cuauhtémoc, una carta de denuncia que harán llegar [también] al licenciado

11 FAHR, “'Razzias' contra homosexuales”, Bandera Socialista, 23 de septiembre de 1978.

12 González de Alba, "Razzia del sábado por la noche”, Unomásuno, 25 de septiembre de 1978.

13 Freddy Sánchez, "Manifestación hoy en la tarde. Homosexuales protestarán por mal trato de policías", Diario de México, 29 de septiembre de 1978. 
Agustín Alanís, procurador de Justicia del D.F.» ${ }^{14}$ Durante el acto se repartieron copias de esta carta y se realizaron pronunciamientos. «Lo más grave del asunto, explicaron los oradores, es que ya en la delegación, el juez calificador, sin informar a los detenidos el porqué del encarcelamiento de que son objeto, sólo les pregunta: ‘Eres homosexual?’». Quienes respondían afirmativamente eran incomunicados, extorsionados y amenazados con ser «quemados» con su familia. En la manifestación, además, no faltaron los hostigamientos. Los manifestantes «permitieron a un grupo de agentes de la Procuraduría fotografiar a cada uno de ellos». ${ }^{15}$

Con todo, la respuesta de las autoridades no fue positiva. Al año siguiente, en octubre de 1979, ante el reclamo de agrupaciones vecinales que asociaban las redadas con mayor seguridad urbana, el general Antonio Durazo Moreno, director de Policía y Transito, reiteró su compromiso. «[C] on su peculiar modo de hablar, les manifestó: 'No me he rajado pues las razias continuarán, porque si nos hemos jactado de ser la ciudad más segura del mundo continuaremos con nuestra misión...'». ${ }^{16} \mathrm{Y}$ así lo harían. Las redadas siguieron asolando a la comunidad homosexual y a otros sectores marginados, en una campaña de moralización social dirigida a la vida nocturna. Para mayo de 1980, las principales agrupaciones que conformaban el MLH en México estaban preparándose para tomar medidas el respecto. En una hoja volante se invita a una parada el 8 de mayo frente a la DGPyT, en la plaza de Tlaxcoaque. En esta hoja se puede apreciar un collage de notas periodísticas que informan de las constantes razzias. El collage está intervenido con letra manuscrita, con mensajes como «esto debe acabar», «tenemos que actuar» y «siguen las redadas (¿y nosotros?...mudos; inmóviles...)». ${ }^{17}$ Además, incluye los nombres de las agrupaciones lésbico-gay Oikabeth, FHAR y Lambda.

Durante la manifestación de la plaza de Tlaxcoaque, las organizaciones del MLH denunciaban, por ejemplo, que los agentes de la DGPyT circulaban en autos «chocolate», que hacían rondines en la Zona Rosa, que acosaban homosexuales y que, una vez apresados, eran golpeados en los separos. «Luego, le piden cierta cantidad para ser liberado, que va de 10 a 20,000, o bien es remitido a la agencia del Ministerio Público como cualquier delincuente. La mayoría de las acusaciones son de robo de automóviles o carteristas». ${ }^{18}$ En la prensa amarillista no faltaron crónicas caricaturescas. Una de ellas se describía a los asistentes manifestándose «ataviados algunos elegantemente, con valiosas joyas en el cuello y dedos, contorsionándose a veces y otras fingiendo la voz». ${ }^{19}$ En otra más, por ejemplo, se les refería como personas de «raras costumbres» ${ }^{20}$.

14 Redacción, “También en México los homosexuales protestan...”, Novedades, 29 de septiembre de 1978.

15 Becerra Acosta, "Protestas por las razzias que realiza la policía...", Unomásuno, 30 de septiembre de 1978.

16 Reyes Estrada, "No me he rajado...", Unomásuno, 24 de octubre de 1979.

17 CAMENA, Fondo I, exp. vis1.

18 Olivares, "Los de la 'Onda Gay' acusan de arbitraria..." Ovaciones, 9 de mayo de 1980.

19 Cabrera, "Lesbianas, 'Cariñosas' y Homosexuales Exigen el Fin de las Redadas", La Prensa, 9 de mayo de 1980.

20 Redacción, "En la Explanada de la Dgpyt Homosexuales Protestan...”, Novedades, 9 de mayo de 1989. 
Según reportaron varios medios, durante la manifestación, un grupo de ocho personas ingresó a las instalaciones de la DGPyT y fue recibido por el coronel Arturo Marabán, jefe operativo. A él entregaron un pliego petitorio en el que se exigía el fin de las redadas y los arrestos masivos, especialmente afuera de las discotecas. En el cuarto punto de este pliego, el colectivo exigía «[q]ue se les permita, como marca la Constitución, el libre acceso a todos los lugares públicos; asimismo, vestirse como mejor prefieran». ${ }^{21} \mathrm{Al}$ final de la manifestación, a la que acudieron también militantes de partidos de izquierda y organizaciones feministas, se convocó a la marcha nacional que se celebraría el 28 de junio con motivo del Día del Orgullo Homosexual. ${ }^{22}$ Estas acciones dan cuenta de una organización homosexual basada en un sentido de urgencia. Según algunas interpretaciones, la movilización homosexual la motivó la coyuntura que ofrecía el antecedente del movimiento estudiantil y el movimiento feminista (Salinas Hernández, 2008: 42), pero sus reivindicaciones fueron desatendidas porque, planteadas en el lenguaje de los nuevos movimientos sociales, tenían «una naturaleza más simbólica, menos concreta y, por ende, más difícil de precisar» (35). Aunque sin duda este primer MLH incluyó un discurso liberacionista de la identidad homosexual, sería erróneo concluir que sus demandas «no planteaban asuntos de tipo material y concreto» (42). Hacerlo sería desatender por completo una faceta central del MLH en estos años.

\section{EUTANASIA AL MOVIMIENTO LILO. LOS DILEMAS SOCIALES DEL MOVIMIENTO}

Con el fin del sexenio de José López Portillo en México, acabó también el régimen de Alfonso «El Negro» Durazo al frente de la DGPyT. Tristemente célebre, Durazo se convirtió en un ícono de la corrupción policiaca, famoso por el destape de sus escándalos de tráfico de drogas y extorsión, en el que estaba involucrada la red de seguridad de la ciudad (González,1983). Esto, sin embargo, no detuvo las campañas de moralización de la vida nocturna que siguieron afectando a la población homosexual junto con otros grupos marginados que habitaban la noche en los centros urbanos.

El 9 de marzo de 1984 la ciudad de México fue el escenario de la que se consideró la redada más grande hasta entonces. Los agentes de la nueva Secretaría de Protección y Vialidad «recorrieron desde las 23 horas hasta las 4:30 horas (...) las más importantes avenidas con el propósito de detener a quienes parecieran dedicarse al oficio más antiguo del mundo». En todo caso, «la medida respondía al fin de extorsionar a las personas capturadas». ${ }^{23}$ La acción se concentró en la Zona Rosa, centro neurálgico de una creciente

21 Cabrera, "Lesbianas, 'Cariñosas' y Homosexuales Exigen el Fin de las Redadas”, La Prensa, 9 de mayo de 1980.

22 Mejía, "mitin contra la represión policiaca a los homosexuales", Bandera Socialista, 19 de mayo de 1980.

23 Tinoco, "Gigantesca Redada. Operación en la Zona Rosa. Detuvieron a 700 Damiselas y Homosexuales", El Sol de México, Edición Mediodía, 10 de marzo de 1984. 
vida nocturna gay, pero abarcó gran parte del centro de la ciudad «con la finalidad de combatir la delincuencia y terminar con la plaga de mujeres de la vida galante y homosexuales que han invadido la zona». ${ }^{24}$ Algunos medios, sin embargo, reportaron la inconformidad que provocó la gigantesca redada, que terminó por afectar también a turistas nacionales e internacionales que disfrutaban de la vida nocturna.

A los pocos días, el semanario Proceso publicó un amplio reportaje de Carlos Monsiváis, en el que se denunciaba lo que parecía ser una política nacional de redadas. Con base en testimonios de la razia del 9 de marzo y de otras más en distintas ciudades de la República, el reportaje argumentaba que, con la excusa de enfrentar la delincuencia, los agentes policiales ocultaban sus propia fechorías: la extorsión y el robo a los sectores más vulnerables de la sociedad. Para Monsiváis, además, esto se hacía para «impedir o liquidar en embrión la conciencia de solidaridad y el ejercicio de la crítica», profundizando así el proyecto de moralización. «Al involucrar prostitutas y homosexuales (los dos sectores más desposeídos de derechos en una sociedad puntualmente autoritaria), la redada se 'legalizaba a sí misma'. Lo que oprime a los 'inmorales' será moral». ${ }^{25}$ Este énfasis en el carácter de clase, es decir, en la forma en que la campaña de moralización afectaba a la población más pobre, comenzó a circular de manera más enfática en los diarios de 1984.

Unomásuno publicó a finales de marzo una columna que afirmaba que, además de afectar a homosexuales y a las nuevas culturas juveniles, las redadas eran una política clasista. ${ }^{26}$ El mismo día, el periódico El Universal también reportaba los abusos de la policía en las redadas ${ }^{27}$ y en Metrópoli se anunciaba una nueva parada de protesta frente a la delegación Cuauhtémoc. ${ }^{28}$ Para entonces, el problema de la arbitrariedad policiaca y su efecto en los sectores más pobres había adquirido sorprendente notoriedad, llegando a los medios de mayor circulación y prestigio. Una hoja volante convocaba a participar de la VI Marcha del Orgullo Lésbico-Homosexual ese año, pero con el nombre «Marcha de la Diferencia». Una joven con apariencia «punk» muestra un cartel que invita «a resistir, bandas unidas contra el agandalle de la tira y las redadas». ${ }^{29}$

Durante la marcha del 30 de junio, la asociación con los «chavos banda», una cultura juvenil afectada por las redadas y formada por jóvenes marginados (algunos en situación de calle), probaría ser profundamente conflictiva para el MLH. La imagen y actitud festiva de travestis, «chavos banda» y demás sectores vulnerables a la arbitrariedad policiaca generó desacuerdo entre los colectivos homosexuales. Algunos de éstos se

24 Redacción, "Arrasaron con Turistas y Mujeres de la Vida Galante (Razzias en la Zona Rosa)", Ovaciones, 10 de marzo de 1984.

25 Monsiváis, "A la escalada de delincuencia la policía opone su propia delincuencia. Las redadas, contacto diario de la autoridad con los ciudadanos más pobres", Proceso, 19 de mayo de 1984.

26 Aguilar Mora, "Razzias clasistas. Gente errante por la calle”, Unomásuno, 30 de mayo de 1984.

27 Fernández, "Abusos de la Policía por las razzias", El Universal, 30 de marzo de 1984.

28 Aguilar Pérez, "Contra las 'razzias' se pronunciaron organizaciones políticas y sindicales", Metrópoli, 30 de marzo de 1984.

29 CAMENA, Fondo I, exp. vis1. 
mostraron más interesados en promover una imagen seria y solemne ante los asesinatos por homofobia y las primeras víctimas del VIH-SIDA que en representar a los sectores más pobres de la ciudad (Mogrovejo, 2000: 132-136). Incluso, algunos militantes hicieron circular un panfleto titulado «Eutanasia al movimiento Lilo», en el que denunciaban la falta de radicalidad del MLH y promovían su desaparición (Brito, 2000: 242). Para la VII Marcha del Orgullo, al año siguiente, los colectivos que originalmente conformaron este primer MLH estarían ya desarticulados y el movimiento lésbico-gay entraría en una nueva etapa, marcada por la introspección y la lucha contra el VIH-SIDA (Díez: 2010).

\section{NO LOS HAGAS ENOJAR O NOS VA PEOR. RESISTENCIA A LA PERSECUCIÓN POLICIACA}

A pesar de las desavenencias, la VII Marcha del Orgullo se llevó a cabo en 1985 gracias a una convocatoria mixta. Durante el recorrido, una manifestante lesbiana fue entrevistada por un diario de la ciudad. Al narrar cómo fue extorsionada por un policía en la Zona Rosa, que la quería apresar por pasear con su pareja, la entrevistada fue confrontada por el periodista. ¿Cómo fue que se había dejado extorsionar si no estaba cometiendo ningún delito? Tendría que haber protestado en la delegación. Su respuesta nos ayuda a entender la lógica detrás de las resistencias cotidianas a la persecución policiaca: «¿Protestar en la delegación? ¿Para que se burlen y sufrir más vejaciones?» ${ }^{30}$ Como ella, a lo largo de este periodo de intensa movilización y reclamo a las autoridades, muchos sujetos se debieron enfrentar frontalmente a la arbitrariedad policiaca. A diferencia de las actitudes de reivindicación propias de la movilización social, con consignas y reclamos, ante la amenaza policiaca los homosexuales actuaron de formas que acataban la autoridad y aceptaban la propia subordinación.

Las crónicas de redadas que circularon en la época dan cuenta de una diversidad de prácticas que lo confirman. Negar la homosexualidad, pagar cuotas, ocultar objetos de valor, cooperar con la autoridad y dar identidades falsas son todas actitudes que ayudaron a los involucrados a salir de una situación de peligro lo más pronto posible y con las menores contrariedades. Los mismos sujetos, además, esperaban de sus pares una cooperación similar. Así lo deja ver, por ejemplo, la crónica de González de Alba en su paso por la delegación. Su actitud provocadora ante la autoridad, acaso alimentada por la seguridad que le brindaban sus conocimientos y su posición de periodista, fue pronto frenada por otros. «¿Quién es este payaso?’ Yo sigo hasta que un vecino, vestido de Travolta, con traje blanco y chaleco, me da un codazo: 'No los hagas enojar o nos va peor.'» En su cónica, González de Alba cuenta haberse aprovechado de la presencia del juez «frente a quien no suele golpearse a los detenidos», para enfrentarse a un policía. Además, con humor, al pedírsele sus datos, entrega el nombre de Pancho Villa.

30 Ríos Navarrete, "Judiciales en la marcha. Homosexual seguro, a las razzias dales duro”, Unomásuno, 17 de julio de 1985. 
Pero no todos tenían la misma suerte ni los mismos conocimientos de la autoridad que González de Alba. Junto a él «[s]e llevan a un muchacho que golpeaba las paredes, lo encierran en uno de los cuartitos, cuando lo sacan le preguntan: ‘¿Ya entendiste?' El muchacho parece que ya entendió». ${ }^{31}$ Particularmente impactantes son las crónicas de la magna redada del 9 de marzo de 1984, en la que se vivió lujo de violencia, según las palabras de un joven profesionista, empleado federal. «A todo mundo lo mismo: 'Soplen, hagan el cuatro'. Luego dar el nombre dos veces, ir hacia el sótano de nueve en nueve, aguantar los golpes. ‘ OÓrale! ¡Ahí les va por mayates!' Y el chingazo». El saqueo de los capturados parecía ser parte importante del botín de las autoridades. «A mí no me quitaron nada. Supe que a otros sí les bajaron lo que llevaban. De cualquier modo, yo metí mi reloj y mi anillo de graduación en los zapatos.» La cuota de 1,500 pesos fue sanción para todos. ${ }^{32}$

Una crónica de ese misma redada, hecha por un joven comerciante, sorprende por pintar una imagen de absoluto caos urbano:

«La delegación Cuauhtémoc era un circo. A las putas y a las vestidas les bajaban los calzones delante de todo mundo, para ver si eran hombres o mujeres. No había policía suficiente. A ratos me parecía una escena de la Alemania nazi, como ves en las películas... En la delegación uno no existe. Ni saliste ni entraste. No hay acta.

Mis respetos para las 'vestidas' (los travestis). Son tan gruesas, están tan acostumbradas a que todo mundo las chingue, que les vale madre. Gritaban: ‘¡Déjenme salir! ¡Pendejos, putos, bola de culeros!', golpeaban la puerta, retaban a los policías, se les iban encima. Luego uno dijo: 'Los homosexuales, fórmense por acá'. Todos nos miramos sacadísimos de onda. Cuando vimos que eran las vestidas las que salían, respiramos. Se oyó un AAAH! De alivio... A una 'vestida' la tuvieron que sacar entre cuatro.» ${ }^{33}$

El miedo a las represalias por ser homosexual generaba una gran ansiedad por la apariencia física, pues ésta podía evitar o provocar la violencia de la policía. Los travestis, por supuesto, eran el principal objeto de esa violencia. «Si no tienes el andar de Pedro Armendáriz o de Pancho Villa te clasifican como sospechoso, te dicen que estás fichado». ${ }^{34}$ En lugar de reivindicar su orientación sexual, negarla se convirtió en una estrategia para sortear conflictos. Así se deja entrever, por ejemplo, en una carta enviada por el activista y periodista Braulio Peralta a La Jornada, en la que denuncia y narra un arresto arbitrario en la delegación Cuauhtémoc.

Peralta cuenta cómo los oficiales se bajaron de sus camionetas detrás del Palacio de Bellas Artes y detuvieron a un amigo suyo. Al confrontar a la autoridad sobre los motivos del arresto, el oficial le responde: «porque tiene cara de homosexual». Aunque

31 González de Alba, "Razzia del sábado por la noche", Unomásuno, 25 de septiembre de 1978.

32 Monsiváis, “A la escalada de delincuencia...", Proceso, 19 de mayo de 1984.

33 Monsiváis, “A la escalada de delincuencia...", Proceso, 19 de mayo de 1984.

34 Fernández, "Abusos de la Policía por las 'razzias"”, El Universal, 30 de marzo de 1984. 
la carta pública de Peralta pretende hacer un reclamo a la homofobia de las autoridades, su breve relación del intercambio con el agente de la ley da cuenta de otro modo de actuar. En lugar de apelar a la injusticia detrás de los motivos del acto de detención, Peralta reclama: «¿Y por lo que no puede ni siquiera comprobar, se lo lleva?» ${ }^{35}$ Este tipo de interacciones evidencia las formas en que los sujetos se tuvieron que enfrentar a la represión cotidiana. Aunque ellos considerasen injustos los motivos de una detención, la negociación con las autoridades sería más efectiva y segura si se trataban de negar las acusaciones.

En todos los reportes destaca, además, el robo, la extorsión y el cobro de multas por cargos administrativos, a menudo inventados. En las crónicas se asoma, también, la existencia de un sistema de «cuotas». Según cuenta una mujer que era transportada a la delegación durante la redada de marzo del 84, «los mismos agentes detuvieron a unas prostitutas, con las que llegaron a un arreglo». ${ }^{36}$ Detalles como éste y, por supuesto, las ya conocidas redes de extorsión que tenían al «Negro» Durazo a la cabeza, permiten intuir la existencia de acuerdos tácitos y preexistentes que dotaban de tranquilidad a la vida nocturna. A cambio de una módica cantidad, a los noctámbulos se les dejaba en paz. Quizás la desaparición de este tolerado sistema de explotación, que cambió para dar paso al desorden de las redadas y la detención arbitraria, fue la que desató la chispa de la confrontación directa.

El rechazo a la represión, el reclamo a las autoridades y la reivindicación de la propia identidad nos sólo fueron resultado del ambiente político, sino de una situación que se volvía repentinamente intolerable. Este tipo de explicaciones, que aquí se plantean como hipótesis a continuar explorando, permiten además establecer un vínculo entre la represión a los homosexuales y el marco conceptual de otros tipos de marginación, en la que ésta significa una explotación material. En palabras de Scott (2010), «estas formas de dominación, que son medios institucionalizados de extraer trabajo, bienes y servicios de una población subyugada, encarnan principios formales sobre la superioridad y la inferioridad, muchas veces con estructuras ideológicas complejas» (46).

Esta interpretación invita también a un reflexión sobre la naturaleza del Estado en el contexto de la represión a los sujetos homosexuales. Según Monsiváis, por ejemplo, «para cientos de miles de personas, el Estado se corporeiza en las redadas y en las rondas de las patrullas». La realidad, sin embargo, nos da cuenta de redes particulares, en que personas específicas dan rienda suelta a su sadismo y despliegan sus ideas de superioridad e inferioridad en clave de género, para obtener así un beneficio propio y entre sus pares. Visto así, cabe pensar en el Estado como una ficción que oculta un complejo entramado de relaciones específicas, vinculadas por el interés de beneficiarse de su legitimidad (Abrams, 1998).

35 Peralta, "El Correo Ilustrado. El Fisgón. Homofobia y razzias en la delegación Cuauhtémoc", La Jornada, 24 de septiembre de 1984.

36 Monsiváis, “A la escalada de delincuencia...", Proceso, 19 de mayo de 1984. 
Finalmente, las ideas que aquí se aventuran no son excluyentes con otras explicaciones. Tienen razón, por ejemplo, quienes atribuyen el origen del MLH a la coyuntura que permitió a unas clases medias y altas articular un mensaje de reivindicación de la identidad (Salinas Hernández, 2008). La repentina expansión de las redadas en la década de los 70 y 80 también significó la diversificación de sus víctimas. Así lo planteó un columnista en su momento:

«Las razzias son clasistas. Cierto es que el celo policiaco se ha extremado tanto que, sobre todo los viernes y los sábados por la noche, un público burgués y clasemediero es cada vez más, también víctima de sus atropellos. (...) Pero, insistimos, las razzias son clasistas.» ${ }^{37}$

La conjunción de estas explicaciones, es decir la arbitrariedad de unas redadas que hacían intolerable la tradicional extorsión de los noctámbulos y, a su vez, la repentina expansión de los afectados por la represión, con suerte ayudarán a darle distintas perspectivas de interpretación al estudio del Movimiento de Liberación Homosexual en México. La liberación no solamente surgió en las mentes de sus ideólogos. También sucedió en las calles.

El lugar común para la interpretación de los movimientos de liberación homosexual en el mundo enfatiza el «chispazo» que se encendió en Nueva York en 1969. Los disturbios que se desataron en el Stonewall Inn han sido concebidos como un punto de inicio de estos movimientos y se han destacado precisamente por la forma en que la resistencia a una redada de la policía devino en un motín. Sin embargo, existen pocas interpretaciones que se separen de la noción de origen y busquen un ejercicio comparativo que dimensione las dinámicas locales. En México, la resistencia a la violencia policiaca no devino en motín. Sin embargo, la movilización de los militantes de la liberación homosexual tampoco puede caracterizarse como una manifestación política e intelectual despegada de las preocupaciones de la violencia cotidiana. Es posible que una clave para la interpretación de la movilización en México se encuentre en un lugar intermedio. Los militantes locales adoptaron un discurso de liberación homosexual, inspirados por los movimientos que habían surgido en el resto del mundo. A su vez, adaptaron sus compromisos políticos a las preocupaciones urgentes de la vida urbana de los homosexuales, promoviendo una movilización que rechazaba las acciones de la autoridad.

Las características de esta dinámica serán, sin duda, estudiadas y descritas más profundamente por una historiografía que está mostrando cada vez mayor vitalidad.

37 Aguilar Mora, "Razzias clasistas. Gente errante por la calle", Unomásuno, 30 de mayo de 1984. 


\section{BIBLIOGRAFÍA}

Abrams, P. (1988): "Notes on the Dificulty of Studying the State", Journal of Historical Sociology, 1.1, 58-89. DOI: https://doi.org/10.1111/j.1467-6443.1988.tb00004.x

Argüello Pazmiño, S. (2014): "Identificaciones en disputa. (Des)construcciones identitarias del Movimiento de Liberación Homosexual (MLH) mexicano, 1968-1984”, en Tarrés Barraza, M.A., L.B. Montes de Oca Barrera y D. A. Silva Londoño (coord.), Arenas de conflicto y experiencias colectivas. Horizontes utópicos y dominación, El Colegio de México, Centro de Estudios Sociológicos, México, 125-160. DOI: https://doi.org/10.2307/j.ctv6mtdb8.7

Bautista, J.C. (2010): "La noche al margen. Brevísima relación de la vida nocturna gay", en Schuessler, M. y M. Capistrán (coords.), México se escribe con J. Una historia de la cultura gay, Editorial Planeta, México, D.F., 209-228.

Beachy, R. (2014): Gay Berlin, Birthplace of a Modern Identity. Vintage Books, New York. DOI: https://doi.org/10.1007/s12119-015-9278-1

Blanco, J.J. (2010): “Ojos que da pánico sonar”, en Schuessler, M. y M. Capistrán (coords.), México se escribe con J. Una historia de la cultura gay, Editorial Planeta, México, D.F., 254-262.

Boivin, R. (2013): "De cantinas, vapores, cines y discotecas. Cambios, rúpturas e inercias en los modos y espacios de homosocialización de la ciudad de México", Revista Latino-Americana de Geografia e Gênero, 4.2, 118-133. DOI: https://doi. org/10.5212/rlagg.v.4.i2.118133

Brito, A. (2010): "Por el derecho a todos los derechos", en Schuessler, M. y M. Capistrán (coords.), México se escribe con J. Una historia de la cultura gay, Editorial Planeta, México, D.F., 240-246.

Butler, J. (2009): "Performatividad, precariedad y políticas sexuales", AIBR, Revista de Antropología Iberoamericana, 4.3, 321-336. DOI: https://doi.org/10.11156/ aibr.040303e

Chauncey, G. (1994): Gay New York, Gender, Urban Culture, and the Making of the Gay Male World, 1890-1940, Basic Books, New York.

De la Dehesa, R. (2010): Queering the Public Sphere in Mexico and Brazil. Sexual Rights Movements in Emerging Democracies, Duke University Press, London. DOI: https://doi.org/10.1215/9780822392743

Díez, J. (2010): “El movimiento lésbico gay 1978-2010”, en Tepichín A.M., K. Tinat y L. Gutiérrez de Velasco (coords.), Los Grandes Problemas de México. Relaciones de Género, El Colegio de México, México, D.F., 135-154.

Gonzalez, J. (1983): Lo negro del Negro Durazo, Editorial Posada, México, D.F.

Huard, G. (2014): Los antisociales. Historia de la homosexualidad en Barcelona y París, 1945-1975, Marcial Pons, Madrid.

Mogrovejo, N. (2000): Un amor que se atrevió a decir su nombre, La lucha de las lesbianas y su relación con los movimientos homosexual y feminista en América Latina, CDAHL, Plaza y Valdés, México, D.F. 
Monsiváis, C. (2010): "Los gays en México: la fundación, la ampliación, la consolidación del guetto", en Que se abra esa puerta. Crónicas y ensayos sobre la diversidad sexual. Editorial Paidós, Debate Feminista, México, D.F., 109-140.

Rodríguez Sánchez, N (2018): “De Cuauhtemotzín a las cervecerías. El control oficial del homoerotismo masculino y la construcción estratégica de la geografía disidente, ciudad de México, 1930-1951”, Estudios Históricos, 68.1, 111-176. DOI: http:// dx.doi.org/10.24201/hm.v68i1.3639

Salinas Hernández, H.M. (2008): Políticas de disidencia sexual en México, Comisión Nacional para Prevenir la Discriminación, CONAPRED, México, D.F.

Scott, J. C. (1976): The moral economy of the peasant: Subsistence and rebellion in Southeast Asia, Yale University Press, New Haven.

Scott, J. C. (2008): Weapons of the weak: Everyday forms of peasant resistance, Yale University Press, New Haven y London.

Scott, J. C. (2010): Los dominados y el arte de la resistencia. Discursos ocultos, Editorial Era, México, D.F.

Scott, J. C. (2014): "Explotación normal, resistencia normal", Relaciones Internacionales, 26, 85-104.

Thompson, E. P. (1971): "The moral economy of the English crowd in the eighteenth century," Past \& present, 50, 76-136. DOI: https://doi.org/10.1093/past/50.1.76

Weeks, J. (2012): "Queer(y)ing the 'Modern Homosexual'", Journal of British Studies, 51.3, 523-539. DOI: https://doi.org/10.1086/664956 